\title{
DA COLÔNIA AO CAPITALISMO DEPENDENTE: NEOLIBERALISMO NA AMÉRICA LATINA
}

\section{From Colony to Dependent Capitalism: Neoliberalism in Latin America}

\author{
Bruno de Oliveira Cruz \\ UFPR, Curitiba-PR, Brasil \\ Juliano Glinski Pietzack \\ UFPR, Curitiba-PR, Brasil
}

\section{Informações do artigo}

Recebido em 28/07/2020

Aceito em 25/10/2020

doi>: 44https://doi.org/10.25247/2447-861X.2020.n250.p429-

Esta obra está licenciada com uma Licença Creative Commons Atribuição 4.0 Internacional.

\section{Como ser citado (modelo ABNT)}

CRUZ, Bruno de O.; PIETZACK, Juliano Glinski. Da Colônia ao capitalismo dependente: o neoliberalismo na América latina. Cadernos do CEAS: Revista Crítica de Humanidades. Salvador/Recife, v. 45, n. 250, p. 429447, maio/ago. 2020. DOI: https://doi.org/10.25247/2447861 X.2020.n250.p429-447

\begin{abstract}
Resumo
A implementação do neoliberalismo na América Latina é um processo contraditório que só pode ser compreendido sob a avaliação da relação de classes no subcontinente. $O$ presente artigo busca relacionar as ideias de Capitalismo Dependente, conforme a teorização de Florestan Fernandes, com o desenvolvimento histórico das doutrinas neoliberais sob a perspectiva da sociologia marxista. A necessidade de expansão desenfreada do Capital já é compreensão clássica das perspectivas críticas das ciências sociais; perante tais aportes teóricos, esse fenômeno levaria necessariamente a uma expansão territorializada dos mecanismos capitalistas, sob a égide do colonialismo, que alcança também os países politicamente independentes da América Latina sob o formato do Capitalismo Dependente, em que a inexistência de uma Revolução Burguesa aos moldes europeus leva ao aburguesamento da oligarquia tradicional, que preserva seus métodos de repressão violentos, mas fagocita os ideais e as inovações do capitalismo central, pois é subserviente ao capital. Frente a tal cenário, o neoliberalismo se consolida, alimentandose da contradição típica da classe dominante local, promovendo - desenvolvimento de uma nova hegemonia pelo convencimento e pela força.

Palavras-Chave: Colonialismo. Imperialismo. Capitalismo
\end{abstract} Dependente. Neoliberalismo.

\section{Abstract}

The implementation of neoliberalism in Latin America is a contradictory process that can only be understood under the account of the class relationship in the subcontinent. This article seeks to relate the ideas of Dependent Capitalism, as theorized by Florestan Fernandes, with the historical development of neoliberal doctrines from the perspective of Marxist sociology. The need for unbridled expansion of Capital is already a classic understanding of the critical perspectives of the social sciences, in view of such theoretical contributions this phenomenon would necessarily lead to a territorialized expansion of capitalist mechanisms, under the aegis of colonialism, which also reaches the politically independent countries of Latin America under the format of Dependent Capitalism, in which the lack of a European-style Bourgeois Revolution leads to the transformation of the traditional oligarchy into bourgeoisie, which preserves its methods of violent repression, but phagocytes the ideals and innovations of central capitalism, because it is subservient to capital. In face of such scenario, neoliberalism is consolidated, feeding on the contradiction typical of the local ruling class, promoting the development of a new hegemony through persuasion and force.

Keywords: Colonialism. Imperialism. Dependent Capitalism. Neoliberalism. 


\section{Introdução}

A introdução do neoliberalismo na realidade latino-americana não ocorreu sem que houvesse uma narrativa de promessas concretamente irrealizáveis e que mascarava suas reais intenções para com um submundo subordinado à divisão internacional do trabalho. Dentre tantas, a racionalização econômica, a superação do subdesenvolvimento, a igualdade política com o Norte Global, o afastamento do fantasma comunista, a superação do passado oligárquico e autoritário compunham um cenário discursivo que permeou espaços políticos e estavam na agenda das agências internacionais emergidas pós-1945.

Contudo, quase 50 anos passados desde o início da primeira experiência de desestruturação dos frágeis elementos de defesa da classe trabalhadora existentes na América Latina, o neoliberalismo se estabeleceu como uma política hegemônica, sem entregar nenhuma de suas promessas. Aliás, suas repercussões imediatas apenas aprofundaram uma constatação iminente: o capitalismo retardatário do Sul Global e a condição de sobre-explorados das trabalhadoras e trabalhadores latino-americanos.

Compreender os motivos que permitem que uma visão econômico-política largamente rejeitada se consolide no Terceiro Mundo não é uma tarefa fácil de se realizar e perpassa por uma compreensão das dinâmicas de classe no capitalismo periférico latinoamericano, marcado essencialmente por seu passado colonial. As relações de classes, as dimensões da dominação burguesa nacional, as demandas dos conglomerados econômicos internacionais e o caráter profundamente complexo da Revolução Burguesa dos países latinos não permitem exames apriorísticos e abstratos, isto é, a complexidade exige um diagnóstico pormenorizado dos elementos concretos que estiveram presentes em uma ascensão burguesa que não se desagarrou dos dinamismos sociais da colonização.

Em verdade, a impossibilidade de desenvolvimento econômico da região pelos instrumentos capitalistas não é novidade e está diretamente envolvida nas relações de surgimento de nossa burguesia intranacional e como essa se relaciona com a burguesia internacional. Não se trata, portanto, de uma mera constatação da precariedade que se estampa sobre as classes sociais frágeis, afinal, a exploração do trabalho é global, mas de oportunizar reflexões que se refiram aos elementos sociais, políticos, econômicos, geográficos, culturais e étnicos próprios do mundo periférico, e não análises imprudentes e desfocadas do objeto. 
A descolonização política não foi capaz de alavancar a descolonização econômica, afinal, nossa "revolução burguesa" não se deu no choque das lutas de classe que desestabiliza e supera estruturas, mas se deu por meio das próprias estruturas superadas, numa metamorfose em que as asas da borboleta são incapazes de carregar o corpo pesado da lagarta, que passa a viver refém dos animais maiores, numa relação de subjugação consciente e adorada.

O colonialismo se desenvolve em capitalismo dependente, o qual absorve as demandas e as inovações do centro, servindo-Ihe como campo de testes e matéria prima para a construção de um projeto de manutenção do poder de classe: o neoliberalismo. Nas terras latino-americanas, o capitalismo assume sua forma ainda mais disruptiva, alia-se com as forças coloniais, absorve as dominações raciais e étnicas, conjura uma busca incessante pela acumulação primitiva com a finalidade de sustentar as crises do capital e, nesse caso, emerge uma opção de modo de produção da vida que desestrutura todos os laços sociais e enlaça o individualismo burguês a níveis extremos: a política neoliberal.

\section{Imperialismo capitalista e a colonização: dominação pelo monopólio e a fragmentação do mundo}

Os dinamismos do capitalismo revelam o caráter cosmopolita da exploração do mercado mundial. No Manifesto Comunista de 1948, Marx e Engels destacavam o permanente sucateamento das obsoletas industrias nacionais, cuja matéria de trabalho passou a advir de regiões remotas, engendrando o fim da realidade do isolamento das regiões e da autossuficiência das nações para expender um intercâmbio e uma interdependência dos países (MARX; ENGELS, 2010). Esse caráter dinâmico e transformativo decorre da própria modificação dos modos de produção da vida das realidades históricas, imbuídas de contradições e de iminentes transformações intrínsecas à totalidade da realidade concreta.

Em face desse caráter metabólico das realidades históricas, o desenvolvimento do capitalismo decorre "da intercorrência do desenvolvimento de forças produtivas, de alterações nas atividades estritamente econômicas, de inovações tecnológicas e organizacionais e de processos sociopolíticos e culturais que envolvem as classes sociais" (NETTO; BRAZ, 2006, p. 169). A ingerência das economias capitalistas não obedece a fronteiras de qualquer natureza, de modo que, conforme Marx e Engels esclareceram no 
volume primeiro do Capital de 1857, mesmo "os povos, cuja produção ainda se move nas formas inferiores do trabalho escravo, da corveia etc., são arrastados pela produção capitalista e pelo mercado mundial, que faz da venda de seus produtos no exterior o seu principal interesse" (MARX; ENGELS, 2017, p. 310).

Em 1916, Lenin demarcava, na obra O Imperialismo fase superior do capitalismo, que independentemente do caráter protecionista ou livre-cambista dos países capitalistas, vigorava a lei geral e fundamental da então fase do desenvolvimento do capitalismo: a constituição de monopólios em atenção à concentração da produção capitalista (LENIN, 2008). Trata-se de um capitalismo que submete uma quantidade enorme de pequenos, médios e até grandes burgueses a uma parte ínfima de financeiros milionários, cujos traços desse imperialismo do capital orienta à socialização total da produção, encaminhando os capitalistas para a permutação da absoluta liberdade de concorrência à socialização completa (LENIN, 2008).

Essa socialização da produção não desestrutura a apropriação privada, porém a retém sob as mãos de poucos capitalistas, de maneira tal que "mantém-se o quadro geral da livre concorrência formalmente reconhecida, e o jugo de uns quantos monopolistas sobre o resto da população torna-se cem vezes mais duro, mais sensível, mais insuportável" (LENIN, 2008, p. 26). Havia um otimismo gritante dos países centrais, especialmente dos Estados Unidos, que se alicerçava como a terra do capitalismo livre expansionista e galgado na ideia de extinguir a controvérsia da escassez e endinheirar os cidadãos do mundo inteiro (DOBB, 1983).

Em 1913, na obra A Acumulação do Capital, Rosa Luxemburgo propicia uma expressão política do imperialismo que remete ao caráter mundialista da acumulação do capital sob um enfoque às dimensões colonizadoras dos países centrais. Parte-se da compreensão de que "o imperialismo é a expressão política do processo de acumulação do capital, em sua luta para conquistar as regiões não-capitalistas que não se encontrem ainda dominadas" (LUXEMBURGO, 1970, p. 392). Evidenciam-se os instrumentos da política colonial, do complexo de empréstimos internacionais, da política de demandas privadas, das guerras, da opressão e da violência, tornando obscuro desvendar as leis rígidas do processo econômico nesse emaranhado de lutas pela violência política (LUXEMBURGO, 1970).

Os traços desse capitalismo monopolista podem ser distinguidos fundamentalmente pela "rigidez dos preços numa ampla faixa de indústrias principais e manutenção das margens 
de lucro, em vez de colapsos de preços; restrição da produção, em vez da redução de custos como remédio favorito dos industriais e estadistas; capacidade excedente e desemprego" (MOBB, 1983, p. 230). Os excedentes de capitais não são destinados ao melhoramento das condições de vida das trabalhadoras e trabalhadores, dado que incorreria na austeridade dos lucros, mas ao acréscimo dessas acumulações por meio da exportação de capitais para países de capitalismos atrasados (LENIN, 2008).

Maurício Dobb (1983) localiza a contradição desse processo de acumulação de capitais: de um lado, a concentração da riqueza e dos lucros advindos da monopolização inclinará os almejos da burguesia a investir cada vez mais, em contrapartida, as possiblidades para investimentos serão decrescidas. Em face desse contexto, "o desfecho dessa contradição deverá ser uma busca intensificada de saídas externas para investimento - um impulso intensificado por penetrar ou anexar esferas que se apresentam em relação à metrópole da indústria monopolista como colônias" (DOBB, 1983, p. 231). Dessa forma, "os países mais avançados (e, nesse período, a liderança estará com a Inglaterra) buscarão matérias brutas e primas nos rincões mais afastados do globo e inundarão todas as latitudes com as suas mercadorias produzidas em larga escala" (NETTO; BRAZ, 2006, p. 172).

Ellen Wood (2001), resgatando as origens do capitalismo, localiza a reestruturação do imperialismo pelas ações coloniais da Grã-Bretanha, pois estimulou "uma expansão, para o exterior, dos mesmos imperativos que estavam impulsionando o mercado interno: os imperativos da produção competitiva e do aumento do consumo" (WOOD, 2001, p. 108). A violência colonial identificada em 1961 por Franz Fanon na obra Os Condenados da Terra, caracteriza pormenorizadamente os objetivos do capital perfilhados após a constituição de uma classe que concentrou as finanças, o comércio e o conhecimento, isto é, "ascensão ao poder propiciou-lhe empreender operações decisivas: industrialização, incremento das comunicações e, pouco depois, busca de mercados ultramarinhos" (FANON, 1968, p. 76).

Em 1974, Amílcar Cabral identificava a transformação do capitalismo após a estruturação de um mundo que não se baseava mais na escravatura, asseverando que o desenvolvimento do capital atingiu níveis altíssimos com as "grandes acumulações de capital, o desenvolvimento industrial, a necessidade de matérias-primas como vos disse, a necessidade de mercados, e então alguns Estados mais desenvolvidos resolveram o seguinte: tomar a África de fato" (CABRAL, 2019, p. 178). Retomando Marx, a respeito da expansão das repercussões trágicas da livre concorrência no contexto do mercado mundial, Eduardo 
Galeano (2015) destaca que "o ingresso da América Latina na órbita britânica, da qual só sairia para se incorporar à órbita norte-americana, ocorreu nos termos desse quadro geral, e nele se consolidou a dependência dos novos países independentes" (GALEANO, 2015, p. 240).

Desse contexto geral percebe-se que a dimensão desse específico imperialismo capitalista não se circunscreveu apenas aos países colonizados em sentido estrito, visto que "o capital financeiro é uma força tão considerável, pode dizer-se tão decisiva, em todas as relações econômicas e internacionais, que é capaz de subordinar, e subordina realmente, mesmo os Estados que gozam de independência política mais completa" (LENIN, 2008, p. 80). No âmago da época das ferrovias, as empresas britânicas tinham grandes concessões de terras, as linhas e o direito de fomentá-las em solo latino-americano, sendo que uma delas, em 1911, a Brazil Railway, estruturou incêndios sistêmicos e expulsões, bem como mortes de várias famílias assentadas na região, o que provocou a denominada rebelião do Contestado (GALEANO, 2015).

Toda a engenhosidade colonial esteve em paralelo com o processo de fragmentação social pela diferenciação das raças, de modo que o capital tanto nunca deixou de alimentar a acumulação primitiva, quanto nunca se obstava de empregar subsídios raciais para empreendê-la (MBEMBE, 2019). Nesse aspecto, convém destacar que a "opulência europeia é literalmente escandalosa porque foi edificada sobre o dorso de escravos, nutriu-se do sangue de escravos, procede em linha reta do solo e do subsolo deste mundo subdesenvolvido" (FANON, 1968, p. 76). Dessa forma, as razões para o processo de colonização se nutriram de variados aspectos, cuja especificidade histórica esclarecia as demandas dos países centrais em expandir a ingerência imperial.

À primeira vista, as razões expostas para justificar o colonialismo eram de ordem econômica, política, militar, ideológica ou humanitária: conquistar novas terras para nelas instalar nosso excedente populacional; encontrar novas saídas para os produtos de nossas fábricas e de nossas minas, assim como as matérias-primas para nossas indústrias; plantar o estandarte da "civilização" entre as raças inferiores e selvagens e penetrar as trevas que as envolvem; garantir, com nosso domínio, a paz, a segurança e a riqueza a tantos desafortunados que nunca puderam conhecer essas benesses; estabelecer em terras ainda infiéis uma população laboriosa, moral e cristã, propagando o Evangelho entre os pagãos, ou então pôr fim, pela via do comércio, ao isolamento engendrado pelo paganismo (MBEMBE, 2019, p. 122).

Os propósitos da exportação de capitais impelem à colonização, através dos mecanismos monopolistas torna-se factível assolar a concorrência, assegurar encomendas e 
concretizar relações imprescindíveis no mercado colonial (LENIN, 2008). O início do século XX desembocou em um processo de dominação global ímpar, que teve repercussões na ordem global econômica, especialmente no que tange ao papel das economias nacionais na acumulação de capital: a divisão internacional do trabalho.

Eduardo Galeano (2015) pondera que, quando Lenin escreveu sobre o imperialismo em 1916, os Estados Unidos tinham menos de vinte por cento da integralidade dos investimentos privados diretos, de raiz estrangeira, na realidade latino-americana. De maneira que, em 1970, continua Galeano (2015), essa parte corresponde aproximadamente a setenta e cinco por cento. Assim, "a partir da Segunda Guerra Mundial, consolida-se na América Latina um recuo dos interesses europeus em benefício do arrasador avanços dos investimentos norte-americanos. E se assiste, desde então, a uma mudança importante no destino dos investimentos" (GALEANO, 2015, p. 273).

Essa dinamicidade da lógica capitalista é identificada por David Harvey (2005) a partir da subscrição da controvérsia do capital excedente, em vista da exposição de como o capital se movimenta no espaço e no tempo para emergir sua própria geografia histórica específica. Em processo de exploração e sobre-exploração, "a atividade capitalista produz o desenvolvimento geográfico desigual, mesmo na ausência de diferenciação geográfica em termos de dotação de recursos e de possibilidades, fatores que acrescentam seu peso à lógica das diferenciações e especializações espaciais e regionais" (HARVEY, 2005, p. 82-83).

A cartografia do capitalismo não esconde seu caráter global e sua dinâmica reiteradamente expansionista, que fragmenta o mundo não apenas para distinguir classes inteiras oprimidas, mas para tornar as relações internacionais entre soberanias uma exploração mundial. Assim, surge um "novo" imperialismo, razão pela qual a difusão das demandas de mercado incumbiu coercitivamente os fazendeiros do Terceiro Mundo à autossuficiência agrícola pelo alinho a culturas inclinadas ao mercado global, este representado por agências internacionais como o Banco Mundial e o Fundo Monetário Internacional (WOOD, 2001).

O relatório da Conferência das Nações Unidas sobre Comércio e Desenvolvimento (UNCTAD), intitulado State Of Commodity Dependence, destacou que mais da metade dos países subdesenvolvidos do mundo são dependentes de commodities, de modo que metade dos países da América Latina dependem de commodities para sustentaram suas economias nacionais (ONU, 2019). De outro lado, conforme destaca Eduardo Galeano (2015), o 
desenvolvimento das indústrias na América Latina foi estruturado pelas economias centrais, não foi alicerçado por uma política planificada e orientada ao desenvolvimento nacional, nem esteve sob a explosão das forças produtivas, nem da detonação dos entrechoques internos. Assim, "a indústria latino-americana nasceu do próprio ventre do sistema agroexportador, para responder ao agudo desequilíbrio provocado pela queda do comércio exterior" (GALEANO, 2015, p. 278).

As exigências de um capitalismo globalizado incumbem as economias periféricas a se submeterem ao julgo das necessidades globais, de absorver as inevitáveis crises capitalistas, e a utilizarem os subsídios coloniais para garantir uma real dependência do Terceiro Mundo. Os celeiros do mundo mantêm a estrutura agrária historicamente consolidada: o latifúndio. Carece a realidade latino-americana de influxos sociais que rompam com a sobre-exploração, não há, de fato, uma elite liberta das amarras dos antigos regimes, pois são detratarias de uma aristocracia. A revolução burguesa da América Latina não é descoberta sem essa devida localização espacial, nem pela mera releitura das experiências do norte global.

\section{América latina, a colonização moderna e o capitalismo dependente}

O processo formativo da sociedade de classes sociais na América Latina necessita de uma adequação empírica e sociológica quando comparadas com as investigações dos países centrais, dado a herança colonial que aflige e se apodera dos dinamismos sociais latinoamericanos. Reflexões centradas do mundo europeu e as suas consecutivas análises abstratas deslocadas à periferia do mundo não abarcam ou representam fielmente a totalidade e as reverberações do mundo colonial. A complexificação do capitalismo mundializado e a partilha do globo tornam as repercussões das revoluções burguesas não redutíveis a esquemas teóricos padronizados e uniformes ao espaço empírico do norte global.

Nos termos do Florestan Fernandes (1976), os países capitalistas "retardatários" possuem especificidades e se estampam com um inédito capitalismo globalizado, de modo tal que a própria burguesia não é a mesma no decorrer do desenvolvimento histórico. Em face das particularidades latino-americanas, em especial a realidade brasileira, Caio Prado Júnior (2005) acentua a imposição de que a resolução dos impasses econômicos, sociais e políticos, bem como as reformas das instituições que se exigem, devem ser localizadas nas mesmas situações em que os embaraços se concretizam. 
Em razão da necessidade de levantar todos esses meandros como integrantes da totalidade do desenvolvimento histórico, deve-se tomar conta das observações de Theotônio dos Santos (2011) quando identifica o quanto teóricos como Lenin, Bukharin e Rosa Luxemburgo têm limitações evidentes nas suas teorias do imperialismo. Afinal, "a pesar de que la dependência debe ser situada em el cuadro global de la teoria del imperialismo, tiene su realidade propia que constituye uma legalidade específica dentro del processo global y que actúa sobre él de esta manera específica" (SANTOS, 2011, p. 357).

Em verdade, trata-se de enfocar na dependência como uma variável integrante que concebe determinadas estruturas internas, traduz abarcar a configuração mesma do desenvolvimento histórico mundial, compreendendo a dependência como uma determinante, e não como meros efeitos da reprodução capitalista (SANTOS, 2011). A revolução burguesa inserida na realidade latino-americana e, especialmente, no contexto do Brasil, requer reflexões próprias, "e não de especulações abstratas acerca da 'natureza' dessa revolução, do seu tipo e de sua correspondência com algum esquema ideal, proposto fora e acima dos fatos concretos e dados imediatamente pela realidade econômica, social e política" (PRADO JR., 2005, p. 42). Nisso reside o substrato material para Ruy Mauro Marini (2013) asseverar que a histórica do subdesenvolvimento da América Latina é o próprio desenvolvimento histórico do sistema capitalista global.

O atraso das economias não centrais é uma elaboração da conjuntura mundial que se explicita em razão da disseminação do capitalismo em escala global, de tal modo que, nas economias subdesenvolvidas, se ache um sistema de opressão interno que se concatena ao plano internacional de dominação (SANTOS, 2011). Em paralelo à consolidação do capitalismo industrial britânico, o século XIX invocou o ambiente latino-americano a integrar com maior altivez o mercado global, fundamentalmente como promotor de matérias-primas e como usuária de uma fatia do conjunto da produção leve europeia (MARINI, 2013).

Como declara Florestan Fernandes (1976), a passagem ao século XXe a totalidade do alargamento da indústria até 1930 no Brasil constituem a evolução interna do capitalismo competitivo. Tais modificações históricas estavam em paralelo à economia neocolonial que cedia à revolução burguesa, mas, ao mesmo tempo, a determinava de acordo com a configuração geográfica do capitalismo, pois, de fato, "a influência modernizadora externa se ampliara e aprofundara; mas ela morria dentro das fronteiras da difusão de valores, técnicas e instituições instrumentais para a criação de uma economia capitalista competitiva 
satélite" (FERNANDES, 1976, p. 206). O registro da revolução burguesa marcava o status conferido a cada país na divisão internacional do trabalho.

Como uma imprescindível tarefa histórica da acumulação primitiva, "a função que assume agora o capital estrangeiro na América Latina é subtrair abertamente uma parte da mais-valia criada dentro de cada economia nacional, o que aumenta a concentração do capital nas economias centrais" (MARINI, 2013, p. 49). O registro da revolução burguesa marcava o status conferido a cada país na divisão internacional do trabalho.

Otra era la situación de América Latina, productora de metales y produtos tropicales: un importante mercado para Europa y no para América Latina, a la cual le sobraban los restos de este mercado y que tenía que pagar grandes sumas a la Corona y a los comerciantes. Todo esto ha conducido a América Latina, después de rotas las limitaciones del período colonial, a un capitalismo dependiente basado en el sector exportador. Las huellas de un régimen colonial exportador dan los parámetros de la América Latina "liberada". No solamente porque se nos arrebataba gran parte de nuestros excedentes, sino fundamentalmente porque nuestras estructuras económico-sociales eran dependientes y las revoluciones liberadoras no lograron cambiar las bases de estas estructuras, dominadas como lo estaban por la oligarquía criolla (SANTOS, p. 360, 2011).

Como um momento histórico importante desse processo de desenvolvimento da economia brasileira, o Plano de Metas 50 anos em 5 esteve sob apoio dos grandes trustes internacionais para estimular o capital nacional tanto por incentivos creditícios quanto pela inflação, a qual decresce os salários e incorpora aos lucros da burguesia (PRADO JR., 2005). Ora, nos termos de Caio Prado Júnior (2005, p. 49) "foi isso que levou, de um lado, ao total eufeudamento da economia brasileira ao capital imperialista e, doutro, à redobrada exploração do trabalho pelo capital (...), e à decorrente concentração e acumulação capitalistas em proporções jamais vistas no Brasil".

A realização da revolução burguesa na realidade brasileira foi intermediada e nutrida por uma reorganização das estruturas do poder que ainda estavam sob a égide do poder oligárquico, de modo que, embora a burguesia avocasse o encargo de instruir a civilidade moderna sob os ideais da Revolução Francesa, "era vantajoso tirar proveito dos tempos desiguais e da heterogeneidade da sociedade brasileira, mobilizando vantagens que decorriam tanto do 'atraso' quanto do 'adiantamento' das populações"' (FERNANDES, 1976, p. 204). A instrumentalização da realidade colonial avassaladora para a instauração da revolução burguesa apareceu tanto como uma necessidade quanto um aproveito da burguesia nacional. 
Na década de 1950, com a ingerência do capital estrangeiro nas terras brasileiras, explicitava-se com maior exatidão a aliança entre a burguesia nacional e internacional: de um lado, o especulador estrangeiro faz uso da sua tecnologia arcaica para produzir lucros semelhantes aos que lograria com uma maquinaria mais atual em seu país originário; de outro lado, o empresariado local produziria mais-valia atípica com a inédita tecnologia (MARINI, 2013). Existem relações amigáveis e contraditórias, mutuamente benéficas e detratarias, sendo essencialmente complexas, pois trata-se de relações de classes intranacionais e internacionais.

Florestan Fernandes (1976) assevera que a burguesia não se constrangia de travar um embate contra a oligarquia, porém a discordância se concretizava circunscrita a um horizonte cultural polarizado em volta de preocupações individualistas e de um imbricado conservadorismo sociocultural e político. A acomodação da burguesia nacional era uma adaptação a um mundo cravado pela herança colonial, que ainda sustentava uma oligarquia enraizada na sociedade brasileira. Quanto à burguesia internacional, "a convergência de interesses burgueses internos e externos fazia da dominação burguesa uma fonte de estabilidade econômica e política, sendo esta vista como um componente essencial para o tipo de crescimento econômico, que ambos pretendiam" (FERNANDES, 1976, p. 207).

Desta forma, a burguesia industrial latino-americana passa do ideal de um desenvolvimento autônomo para uma integração direta com os capitais imperialistas, dando lugar a um novo tipo de dependência, muito mais radical que a anterior. O mecanismo da associação de capitais é a forma que consagra esta integração, que não apenas desnacionaliza definitivamente a burguesia local, como também, entrelaçada à diminuição relativa do emprego de mão de obra própria do setor secundário latino-americano, consolida a prática abusiva de preços como meio para compensar a redução concomitante do mercado, tendo em vista que os preços se fixam segundo o custo de produção das empresas tecnologicamente mais atrasadas. 0 desenvolvimento capitalista integrado reforça o divórcio entre a burguesia e as massas populares, intensificando a superexploração a que estas estão submetidas e negando-lhes sua reinvindicação mais elementar: o direito ao trabalho (MARINI, 2013, p. 62).

A realidade colonial, a revolução burguesa brasileira, o conservadorismo burguês atrelado ao poder oligárquico, bem como a noção moderna de imperialismo expõem como os influxos teóricos eurocentrados são insuficientes. As acepções dos intelectuais a serviço do capital, que detratam a realidade latino-americana culpando os marginalizados pela marginalização, suprimem a observação geral de dominação a nível mundial e suas correlações com os dinamismos sociais internos. Como destaca Vânia Bambirra (1971, p. 36), 
"em los países cuya industrialización se inicia des'pués del 45, ésta va a ser promovida diretamente por los capitales extranjeros, eliminando desde um princípio la posibilidad de desarrollo de empresários industriales nacionales".

Os conflitos do século XX não escondem as particularidades de uma violência política, social e econômica do imperialismo, nem muito menos estancam o empreendimento dos atores em específico. E, nesse caso, os Estados Unidos assumiram papel relevante. Conforme destaca Vânia Bambirra (1971), no momento pós-guerra (1945) os Estados Unidos empreenderam sua expansão econômica e militar, de modo tal que seu almejo era expandir para o mundo inteiro o complexo industrial-militar, sob a direção de que, por figurarem como superpotência, teriam o direito e a força necessária para intervir concretamente no mundo periférico na forma que julgassem conveniente. O financiamento das ditaduras latinoamericanas do século XX pelos Estados Unidos angariou sujeitos que se comprometiam em outorgar o imperialismo que ainda estava em desenvolvimento e em estancar movimentos insurgentes.

No período do pós-guerra, boa parte do mundo não-comunista estava aberto ao domínio norte-americano mediante táticas desse tipo. Isso se tornou o método preferido de combate à ameaça de rebeliões e de revoluções comunistas, envolvendo uma estratégia antidemocrática (e ainda mais enfaticamente antipopulista e anti-socialista/comunista) da parte dos Estados Unidos que levou o país a firmar cada vez mais alianças com repressivas ditaduras militares e regimes autoritários (claro que de modo mais espetacular na América Latina) (HARVEY, 2008, p. 37).

A Guerra Fria era um ambiente necessário para a expansão da política econômica estadunidense para as economias dependentes: o neoliberalismo. Conforme destaca Eric Hobsbawn (2016), quando os Estados nacionais perderam a potência econômica, sobretudo após a crise de 1973, a única alternativa restante era o neoliberalismo. No Chile, ambiente primeiro da experiência neoliberal, "uma ditadura militar terrorista permitiu a assessores americanos instalar uma economia de livre mercado irrestrita, demonstrando assim, aliás, que não havia ligação intrínseca entre o livre mercado e a democracia política" (HOBSBAWN, 2016, p. 399). 


\section{O projeto neoliberal: poder de classe na estrutura colonial}

Ainda que muito debatida e criticada, não existe no campo das ciências sociais uma noção unificada de neoliberalismo. No entanto, frequentemente é empregada de forma equivocada como uma superestrutura concebida apoliticamente, a qual engloba todas as facções que disputam o Estado após seu surgimento - com óbvia exceção dos iluminados que a criticam - implicando que às forças nacionais cabe ou abraçá-lo de forma voluntária ou ser forçadas a aceitá-lo (FERNANDES; BORGES, 2008). É certo que existe uma infinidade de escolas econômicas e visões teóricas que são colocadas como neoliberais, bem como o arcabouço teórico e político do neoliberalismo pode ser analisado a partir de diversas óticas, a depender de em qual contexto específico se coloca, especialmente ao se considerar que, longe de mera tradição econômica, o neoliberalismo se difunde para diversos espaços de sociabilidade, podendo ser colocado tanto como um método de governabilidade por distanciamento, quanto como parte integrante de uma lógica biopolítica (FOUCAULT, 2008).

No entanto, ao partirmos da análise marxista e da observação da questão da luta de classes, uma análise se sobressai, a qual observa o neoliberalismo enquanto um projeto de restauração do poder de classe, portanto, teria um fim específico e bem declarado: a submissão da classe trabalhadora (HARVEY, 2007). Tal compreensão invoca os elementos concretos da inserção do neoliberalismo na seara do Terceiro Mundo, obstando de formulações gerais e abstratas. Essa pretensão de definir objetivamente o neoliberalismo se deve ao fato de que "tudo indica que a doutrina é nada mais do que uma cobertura ideológica para uma prática sem princípios, em função de interesses econômicos concretos que nunca poderão ser identificados com uma construção teórico-formal que ignora totalmente a realidade histórica" (SANTOS, 2004, p. 57).

O primeiro teste de aplicação em larga escala dos ideais neoliberais foi a ditadura militar do Pinochet (1973-1990), no Chile, na constituição de um Estado Neoliberal, aparato com função de facilitar as condições de acumulação de capital lucrativo, tanto para as classes dominantes nacionais quanto internacionais, segundo a definição do David Harvey (2007). Não é à toa que esse primeiro experimento se deu em terras latino-americanas. A disposição de uso dos meios violentos pela classe dominante local permite mudanças estruturais no funcionamento do aparato estatal mais arriscadas e com menor oposição. Pinochet teve à 
sua disposição os meios de reprimir a oposição e minimizar os efeitos políticos da catástrofe que representou as suas primeiras reformas.

Em 1982, o Chile passou por um colapso bancário, o qual levou a uma redução de 13,6\% do PIB nacional e elevou a taxa de desemprego à margem de 25\% (CEPAL, 2010), mas, ainda assim, o governo militar se manteve firme, algo inimaginável sob qualquer outro regime. O controle e a desarticulação dos sindicatos ocuparam importante papel na consolidação dessas ideias no Chile, de maneira tal que a incapacidade de repetir essas mesmas estratégias contra os sindicatos peronistas na Argentina é uma das razões, identificadas por Tomás Undurraga (2015), pelas quais o neoliberalismo não alcançou tanto sucesso no solo argentino.

Essa disposição para o uso da força não se expressa apenas em momentos de regimes totalitários, mas está sempre presente como uma ameaça silenciosa no universo político latino-americano, seja forçando governos de caráter anti-neoliberal a mediar algumas demandas, seja criando um fator de estabilidade em governos sem nenhum apoio popular, como o de Michel Temer (2016-2018), no Brasil, e os sequenciais governos do PRI no México.

Após o imenso sucesso no teste em terras colonizadas, as táticas neoliberais foram importadas para a América do Norte e Europa, modelando-se, em cada país, às necessidades encontradas. Afinal, se observarmos o neoliberalismo enquanto projeto, mais do que um ideário teórico, veremos que ele está disposto a contradizer os seus fundadores em vista de atingir o objetivo. Em razão dessa acepção, Harvey pontua que o neoliberalismo se constitui enquanto "sistema de justificação e legitimação para qualquer coisa necessária a ser feita para alcançar tal objetivo" (HARVEY, 2007, p. 19).

Nesse intento, o neoliberalismo é uma doutrina de imenso sucesso, de forma que os níveis de desigualdade social e controle de capital, no início do século XXI, se assemelham aos anteriores à segunda guerra mundial (HARVEY, 2007), que se concretizou por meio da desconstrução dos mecanismos de organização social e proteção à classe trabalhadora edificados no pós-guerra. Na América Latina, a lógica do capitalismo dependente encontra o neoliberalismo e não o renega, mas o absorve e se transforma com ele, pois seu caráter dependente exige o acompanhamento da evolução das sociedades centrais hegemônicas, sem, no entanto, abandonar a dependência (FERNANDES, 1975).

Esse acompanhamento não se faz de forma forçada ou pelo mero voluntarismo como, muitas vezes, se expressa na literatura crítica (FERNANDES; BORGES, 2008), mas se coloca 
no próprio dinamismo da lógica colonial e dependente do capitalismo latino-americano, em que a classe dominante continua a tentativa de replicação do modelo oligárquico tradicional (FERNANDES, 1975), de forma que não quer e não tem condições de superar a própria dependência. Não quer superar, pois se beneficia do importe das estruturas capitalistas externas e do combate a visões "subversivas", e é incapaz devido às condições estruturais e dinâmicas (que envolvem a capacidade tecnológica, de disposição de capital, de formação técnica e instituições jurídico-políticas) que impossibilitam a superação do subdesenvolvimento por meio da burguesia nacional nos países de capitalismo periférico e colonizado (FERNANDES, 1975).

$\mathrm{Na}$ abertura dos países latino-americanos para o mercado neoliberal, que se deu nas décadas de 80 e 90, as privatizações tiveram fundamental importância, nelas essa relação entre burguesia nacional e internacional foi reafirmada. Enquanto as grandes empresas estatais e os sistemas de proteção ao trabalhador são vendidos para multinacionais, o que restou de territórios de uso coletivo, como os ejidos no México, são inseridos na lógica da propriedade privada, alimentando uma pequena burguesia nacional, que é subserviente e dependente do capital internacional (HARVEY, 2007).

Assim, a estrutura colonial-dependente absorve o neoliberalismo e se fortalece com ele, pois na submissão da classe trabalhadora mundial encontra terreno fértil na América Latina. Aqui há uma classe dominante disposta a usar de meios antidemocráticos para alcançar seus objetivos, uma estrutura econômica que nunca se desenvolveu de forma autônoma e jamais conseguiu construir as bases da social democracia e do Welfare State tal como na Europa. Sinteticamente, a pretexto de análises otimistas neoliberalizantes, "em boa parte da América Latina, a neoliberalização produziu ou estagnação (na 'década perdida' de 1980) ou surtos de crescimento seguidos por colapso econômico" (HARVEY, 2008, p. 168).

Em verdade, enquanto o neoliberalismo encontra dificuldades para se alojar na Europa, como indica os dados acerca dos gastos públicos nos principais países da região (FERNANDES; BORGES, 2008), na América Latina ele tem mais sucesso, a menor ou maior escala, a depender do país e do período. Contudo, não apenas de força bruta se consolida o capitalismo dependente, mas também exige uma formulação teórica e a composição de uma burocracia técnica, sem a qual o neoliberalismo não triunfaria. A construção de um consenso neoliberal perpassa pela composição de todo um novo contexto de ideias econômicas sobre o senso comum da ideologia burguesa (HARVEY, 2007), determinando não apenas as 
soluções para os problemas vigentes, mas estabelecendo a própria construção dos problemas a serem tratados pela intervenção pública e não o faria sem estruturas de coalizão de defesa formadas por intelectuais, think tanks, entre outros (FERNANDES; BORGES, 2008).

Em verdade, conforme destaca Tomás Undurraga (2015), a força do neoliberalismo chileno na constituição de uma geração de economistas monetaristas, influenciados pelos "chicago boys", permitiu a mediação entre governo e sociedade. Tal fenômeno seria impossível sem a implantação das ideias neoliberais em importantes universidades da região, com o auxílio de planos de investimento e intercâmbios estadunidenses.

Tal implementação de uma nova hegemonia não se limita aos espaços tradicionais de defesa da classe dominante, mas se constrói inclusive em aparatos nos campos típicos da classe trabalhadora, tal como no sindicalismo. O caso brasileiro é rico em exemplos, seja na formação de centrais sindicais defensoras do paradigma neoliberal, como a Força Sindical, seja no enfraquecimento interno das centrais anti-neoliberais, como a CUT (BOITO; RANDALL, 1998).

Assim, na América Latina, o neoliberalismo se alimenta das contradições históricas da classe dominante, enquanto se estabelece como paradigma econômico da democratização política por meio da renovação das concepções hegemônicas, desestruturando seus adversários pela repressão violenta. Esse caráter contraditório do neoliberalismo evidencia sua identidade de projeto de retomada do poder de classe e realimenta as condições essenciais do capitalismo dependente que persegue o subcontinente latino-americano. É plenamente compatível com as velhas tradições oligárquicas, em verdade, é também mecanismo de defesa das mesmas.

\section{Conclusão}

O capitalismo sempre foi um regime transnacional, que não conhece fronteiras ou limites, mas, em sua fase posterior, caracterizada pelo aspecto monopolista e por uma exigência de acumulação de capital e expansão de mercados, se desenvolve em seu aspecto imperialista, que reordena a divisão internacional do trabalho, subordinando as nações periféricas ao centro do sistema. O colonialismo do século XIX e XX é fruto direto dessa necessidade de expansão, ele se faz pelo alargamento das fronteiras e subjugação dos 
continentes asiático e africano, mas também sobre as nações já independentes politicamente que estão à margem do capitalismo central.

Na América Latina, esse processo é bem conhecido, configura-se na permanência das instituições coloniais, em um capitalismo dependente, subalterno, mas que, ainda assim, é necessário, seja para garantir o afluxo de commodities, seja para comprar os produtos de exportação metropolitanos. Nesse sistema, que convive com duas épocas históricas, o desenvolvimento das classes é eminentemente contraditório, caracterizado por revoluções passivas e marcado por uma burguesia em conluio com a oligarquia.

Essa classe dominante não rejeita o neoliberalismo, mas o alimenta e usa-o como meio de sobrevivência, quando encontra as relações do capitalismo contemporâneo ela meramente se adapta, mantém seu domínio de força e tradição, aliado a mecanismos de convencimento "democráticos", faz da sua contradição a do próprio neoliberalismo. A soma desses mecanismos de força e de construção de consenso marca a importação do neoliberalismo na América Latina, afinal é o modus operandi da elite colonizada, que abraça as ideias estrangeiras sem questioná-las e não aceita ser questionada. A classe dominante latino-americana está disposta a abdicar dessa dominância no plano internacional para aumentar os lucros e salvar seu status de classe dominante dos sobre-explorados, ao final, o inimigo ainda é comum, a classe trabalhadora.

\section{Referências}

BAMBIRRA, Vânia. Diez años de insurreccion em america latina. v. 1. Santiago: Prensa Latinoamericana, 1971.

BOITO JR., Armando; RANDALL, Lauta. Neoliberal Hegemony and Unionism in Brazil. Latin American Perspectives, vol. 25, n. 1, p. 71-93, jan. 1998.

CABRAL, Amílcar. Passamos a ser arrastados pela História dos países da Europa. In: MANOEL, Jonas; FAZZIO, Gabriel Landi (org.). Revolução africana: uma antologia do pensamento marxista. 2. ed. São Paulo: Autonomia Literária, 2019.

CEPAL. Anuario Estadístico de América Latina y el Caribe. Santiago de Chile: Naciones Unidas, 2010.

DOBB, Maurice. A evolução do capitalismo. São Paulo: Abril Cultural, 1983.

FANON, Franz. Os condenados da terra. 42. ed. Rio de Janeiro: Civilização Brasileira, 1968. 
FERNANDES, Antônio Sérgio Araújo; BORGES, André. Ideias Fora do Lugar: O Neoliberalismo como Categoria de Análise das Políticas Sociais no Brasil. Organizações \& Sociedade. v. 15, n. 46, p. 13-37, jul./set., 2008.

FERNANDES, Florestan. A revolução burguesa no Brasil. 2. ed. Rio de Janeiro: Zahar Editores, 1976.

FERNANDES, Florestan. Capitalismo Dependente e Classes Sociais na América Latina. 2 ed. Rio de Janeiro: Zahar Editores, 1975.

FOUCAULT, M. The Birth of Biopolitics: Lectures at the College de France 1978-1979. New York: Palgrave Macmillan, 2008.

GALEANO, Eduardo. As veias abertas da América Latina. Porto Alegre: L\&PM Editores, 2015 .

HARVEY, David. A Brief History of Neoliberalism. New York: Oxford University Press, 2007.

HARVEY, David. O neoliberalismo: história e implicações. São Paulo: Edições Loyola, 2008.

HARVEY, David. O novo imperialismo. 2 ed. São Paulo: Edições Loyola, 2005.

HOBSBAWM, Eric. Era dos extremos: o breve século XX 1914-1991. 2. ed. São Paulo:

Companhia das Letras, 2016.

LENIN, Vladimir llitch. O imperialismo: fase superior do capitalismo. 4. ed. São Paulo: Centauro, 2008.

LUXEMBURGO, Rosa. A acumulação do capital: estudo sobre a interpretação econômica do imperialismo. Rio de Janeiro: Zahar Editores, 1970.

MARINI, Ruy Mauro. Subdesenvolvimento e revolução. 4. ed. Florianópolis: Insular, 2013.

MARX, Karl; ENGELS, Friedrich. Manifesto comunista. 1. ed. São Paulo: Boitempo, 2010.

MARX, Karl; ENGELS, Friedrich. O capital: crítica da economia política: livro I: o processo de produção do capital. 2. ed. São Paulo: Boitempo, 2017.

MBEMBE, Achille. Crítica da razão negra. 3. ed. São Paulo: n-1 edições, 2019.

NETTO, José Paulo; BRAZ, Marcelo. Economia política: uma introdução crítica. v. 1. São Paulo: Cortez, 2006.

ONU. Relatório da Conferência das Nações Unidas sobre Comércio e Desenvolvimento (UNCTAD). State Of Commodity Dependence. Disponível em: 
https://unctad.org/en/PublicationsLibrary/ditccom2019d1_en.pdf?utm_source=UNCTAD+ Media+Contacts\&utm_campaign=dac8a4db70-

EMAIL_CAMPAIGN_2019_05_14_02_08\&utm_medium=email\&utm_term=0_1b47b7abd3dac8a4db7o-64976393\&goal=0_1b47b7abd3-dac8a4db7o-64976393

PRADO JR.; Caio. A revolução brasileira. In: PRADO JR., Caio; FERNANDES, Florestan. Clássicos sobre a revolução brasileira. 4. ed. São Paulo: Expressão Popular, 2005.

SANTOS, Theotonio dos. Imperialismo y dependencia. Caracas: Fundación Biblioteca Ayacucho, 2011.

SANTOS, Theotonio dos. Do terror à esperança: auge e declínio do neoliberalismo. São Paulo: Ideias e Letras, 2004.

UNDURRAGA, Tomás. Neoliberalism in Argentina and Chile: Common antecedents, divergent paths. Revista de Sociologia e Política, v. 23, n. 55, p. 11-34, set. 2015.

WOOD, Ellen Meiksins. A origem do capitalismo. Rio de Janeiro: Jorge Zahar, 2001.

\section{Detalhes dos autores}

Bruno de Oliveira Cruz

Graduando em Direito pela Universidade Federal do Paraná. Integrante do Programa de Educação Tutorial (PET Direito), UFPR. Integrante do Centro de Estudos da Constituição (CCONS) pelo núcleo de pesquisa Direito Administrativo, Urbanístico, Ambiental e Desenvolvimento (PRO POLIS), UFPR. Integrante do grupo de extensão e pesquisa LABÁ - Direito, Espaço e Política, UFPR. E-mail: cruz.o.bruno@gmail.com.

Juliano Glinski Pietzack

Bacharel em Direito pela Universidade Federal do Paraná. Pós-Graduando em Direito Eleitoral pelo CERS. Pesquisador do Núcleo de Investigações Constitucionais (NINC), UFPR. E-mail: julianopietzack@gmail.com. 